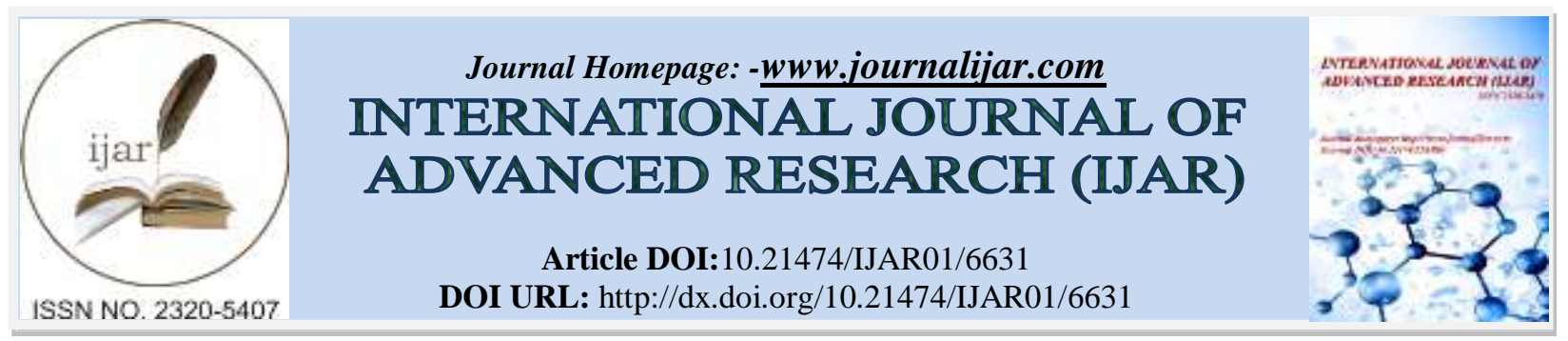

RESEARCH ARTICLE

\title{
EFFECTS OF CONCENTRIC VERSUS ECCENTRIC STRENGTH TRAINING OF QUADRICEPS MUSCLE ON FUNCTIONAL OUT COME IN PATIENTS WITH BILATERAL OSTEOARTHRITIS OF KNEE.
}

Arvind Tomar ${ }^{1}$ and Madhusudan Tiwari ${ }^{2}$.

1. Assistant Professor, Faculty of Physiotherapy, Mahatma Gandhi University of Medical Sciences \& Technology, Jaipur, Rajasthan.

2. Associate Professor \& In charge Dean, Faculty of Physiotherapy, Sankalchand Patel University, Visnagar, Gujarat.

Manuscript Info

Abstract

Manuscript History

Received: 24 December 2017

Final Accepted: 26 January 2018

Published: February 2018

Copy Right, IJAR, 2018,. All rights reserved.

\section{Introduction:-}

Osteoarthritis is the most common type of arthritis affecting synovial joints characterized by degenerative structural remodeling of joint cartilage and of underlying subchondral bone, which again lead to pain and disability. Osteoarthritis of knee is the most common form of osteoarthritis. Among us adults of 30 year of age or older, symptomatic disease in knee occurs in approximately $6 \%$ and hip OA is roughly $3 \%$.

In a community based survey, the incidence and prevalence of disease increased 2-10 fold from 30 to 65 years of age and increased further thereafter. Pain that increases when you are active, but gets a little better with rest swelling feeling of warmth in the joint stiffness in the knee, especially in the morning or when you have been sitting for a while decrease in mobility of the knee, making it difficult to get in and out of chairs or cars, use the stairs, or walk creaking, crackly sound that is heard when the knee moves.

Quadriceps strength is strongly associated with knee pain and disability and progression of joint damage leading to osteoarthritis. Functional performances were much worse for patients with O.A. knees and were most strongly influenced by quadriceps weakness as determinant of disability.

Most commonly used strengthening exercise for O.A. knee are isometric and is kinetic exercise out of which isotonic exercise have been found to be more effective. Isotonic exercises include concentric or eccentric strength training. Isotonic exercises are dynamic form of exercise, which is carried out against a constant or variable load as a muscle lengthens or shortens through the available range of movement. Dynamic strength, muscular power and endurance can be developed by isotonic exercise. Over last few decades, there have been evidences of links between concentric and eccentric strength training exercise in improving muscle strength. 
One study done by Tiwari $\mathrm{M}$ et al concluded that combined (Quadriceps and Hamstrings) isotonic Exercises are better than isolated Quadriceps isotonic Exercises in terms of pain reduction as measured by Visual Analogue Scale and improvement in function as measured by Step Test and Walking speed (Tiwari M et al,2015).

Hortobagyi in his study on adaptive response of muscle lengthening and shortening said that eccentric exercise are associated with greater neural adaptations and muscle hypertrophy than concentric exercise. An article on concentric and eccentric quadriceps contraction says that concentric contraction are better than eccentric contraction as all fibers of the muscle are recruited in concentric contraction where as only few fibers are recruited with eccentric contraction.

Although there are various studies about the effect of concentric and eccentric strength training in improving muscle strength, but which of the two is more effective in improving functional performance is inadequately studied and still requires attention

Hence, there is an effort to find out the effectiveness of concentric versus eccentric strength training of quadriceps muscle on functional outcome in patients with primary osteoarthritis as quadriceps muscles on functional outcome in patient with primary osteoarthritis as quadriceps weakness in osteoarthritis of knee leads to functional impairment.

\section{Material and Methods:-}

A sample of convenience of 60 patients who were diagnosed with bilateral primary OA Knee and who fulfilled the inclusion criteria were referred to outpatient physiotherapy department of Nootan General Hospital \& Nootan College of Physiotherapy, SPU, Visnagar and after obtaining informed consent they recruited for this study. A sample of 60 patients was assigned in two groups, the Concentric Exercise group or the Eccentric Exercise group. Inclusion Criteria: Both Male and Female age ranged between 50 to 65 Years, clinically diagnosed Bilateral Primary Osteoarthritis subjects graded 2 or 3 based on radiographic grading scheme for O.A.

Exclusion Criteria: Clinically diagnosed Unilateral O.A and Secondary O.A. Subjects, history of faints, Vertigo, Diabetes Mellitus, Convulsion and other condition that may impair balance, History of major knee and ankle trauma, neuromuscular and cardiovascular problems.

Instruments used: A high chair or couch, a foot stool to support patient's feet, Weight cuffs of different weights 0.5 to $10 \mathrm{kgs}$, which could be fastened to patient's feet with velcro.

\section{Procedure:-}

Group- 1 Concentric Exercise Group: Subject was asking to extend the leg actively and was given hand support at ankle through the range while lowering the weight to avoid eccentric contraction of quadriceps; this causes isolated concentric contraction of quadriceps. Subjects were allowed to perform 20 repetitions with $50 \%$ of 10 RM weight, frequency -4 days a week and duration- 6 week.

Group- 2 Eccentric Exercise Group: Subject leg was extended passively by therapist $0^{0}$ of knee flexion with hand support at ankle and then the patient was asked to lower the leg active at $90^{\circ}$ of knee flexion. This causes eccentric quads contraction. Passive extension was give to avoid concentric contraction of quadriceps muscle. Subjects were allowed to perform 20 repetitions with $50 \%$ of $10 \mathrm{RM}$ weight, frequency -4 days a week and duration- 6 week.

\section{Outcome measures:-}

WOMAC: Western Ontario and Mcmaster Universities osteoarthritis index pain and disability: this contains five question concerning severity of pain during various activities, each scored $0-4$ subjects were asked to grade level of pain overall rather than separately for each knee. Scores were summated to produce a global pain score from 0 16 with higher scores indicating more knee pain.

Functional Disability Index (FDI): is expressed on a scale from 0-3 unit, representing the mean of eight domain scores. Haq - Di of 0 indicates no functional disability, while disabilities index of 3 indicates severe disability.

\section{Data Collection:-}

Data was collected on $1^{\text {st }}$ day (Pre Test) and at the end of $2^{\text {nd }}$ Week, at the end of $4^{\text {th }}$ week $\&$ at the end of $6^{\text {th }}$ week. Appropriate statistical test was used to analyze the data. 


\section{Data Analysis:-}

Analysis of variance is an extremely useful statistical technique that is used when multiple sample cases are involved. The basic principal of ANOVAs test is for differences among the means of the population by examining the amount of variation within each of these samples, relative to the amount of variation between the samples. It includes following steps. The total number of subject $\mathrm{N}=60$ based on convenient sampling were divided in to two equal groups. Group 1 (Concentric Training) $\mathrm{N}=30$ And Group 2 (Eccentric Training ) N = 30. Group 1 consisted of 12 males and 18 females where as group 2 consisted of 18 males and 12 females The data was analyzed using unpaired $t$ test to compare the significance of difference in pre and post treatment scores between the groups.Using the statistical packages scores obtained using WOMAC and Functional disability index are tabulated in the terms of mean, standard deviation and $t$ values as follows.

\section{Results:-}

Comparisons of both groups for the homogeneity Test of homogeneity of variances: The homogeneity of the data in the two groups was analyzed by using One -Way ANOVA, showed that the significance was greater than $\mathrm{p}=0.05$ and hence were homogenous

Table -1:- Homogeneity for WOMAC ANOVA

\begin{tabular}{|l|l|l|l|l|l|}
\hline Variables & $\begin{array}{l}\text { Sum Of } \\
\text { Squeres }\end{array}$ & Df & Mean Square & F & Sig \\
\hline Between Groups & 2885.200 & 17 & 169.718 & 1.014 & .502 \\
\hline Within Groups & 2008.667 & 12 & 167.389 & & \\
\hline & 4893.867 & 29 & & & \\
\hline
\end{tabular}

Interpretation: The ANOVA test table give the $\mathrm{f}-$ value for significance of variance and as all the values have significance greater than $\mathrm{p}=0.05$ the values are considered homogenous

Table- 2:- Comparison of both groups for homogeneity

Test of Homogeneity of variances: The homogeneity of the data in the two groups was analyzed by using one -way ANOVA, showed that the significance was greater than $\mathrm{p}=0.05$ and hence were homogenous.

Homogeneity for functional disability index ANOVA

\begin{tabular}{|l|l|l|l|l|l|}
\hline Variables & Sum of Squares & Df & Mean Square & F & Sig \\
\hline Between Groups & .270 & 2 & .135 & 1.020 & .374 \\
\hline Within Groups & 3.572 & 27 & .132 & & \\
\hline Total & 3.842 & 29 & & & \\
\hline
\end{tabular}

Interpretation: The ANOVA test table give the $\mathrm{f}$ - value for significance of variance and as all the values have significance greater than $\mathrm{p}=0.05$ the values are considered homogenous.

Table- 3:- Mean Improvements

\begin{tabular}{|l|l|l|l|}
\hline Womac & Osteoarthritis & Index & \\
\hline Variables & $2^{\text {nd }}$ Week & $4^{\text {th }}$ Week & $6^{\text {th }}$ Week \\
\hline Group 1 & 35.8 & 28.26 & 17.73 \\
\hline Group 2 & 38.5 & 26.9 & 14.4 \\
\hline
\end{tabular}

Interpretation: The above table shows that were significant mean improvements in functional out com scores of both groups when measured with womac index.

Table- 4:- Mean Improvements

\begin{tabular}{|l|l|l|l|}
\hline Functional & Disability & Index & \\
\hline Variables & $2^{\text {nd }}$ Week & $4^{\text {th }}$ Week & $6^{\text {th }}$ Week \\
\hline Group 1 & 1.5 & 0.8 & 0.30 \\
\hline Group 2 & 1.4 & 0.88 & 0.38 \\
\hline
\end{tabular}

Interpretation: The above table shows that were significant mean improvements in functional out com scores of both groups when measured with functional disability index 
Table- 5:- WOMAC Osteoarthritis index

\begin{tabular}{|l|l|l|l|l|}
\hline Variables & Mean & S.D & 't Value & $\begin{array}{c}\text { 't Value From } \\
\text { Table }\end{array}$ \\
\hline Group 1 & 29 & 7.96112 & 3.86627 & 3.646 \\
\hline Group 2 & 32.33 & 4.648 & & \\
\hline
\end{tabular}

\section{Interpretation:}

The above table clearly shows that the result are significant at $\mathrm{p}=0.05$ as $\mathrm{t}$ - value is greater than the table $\mathrm{t}$ value.

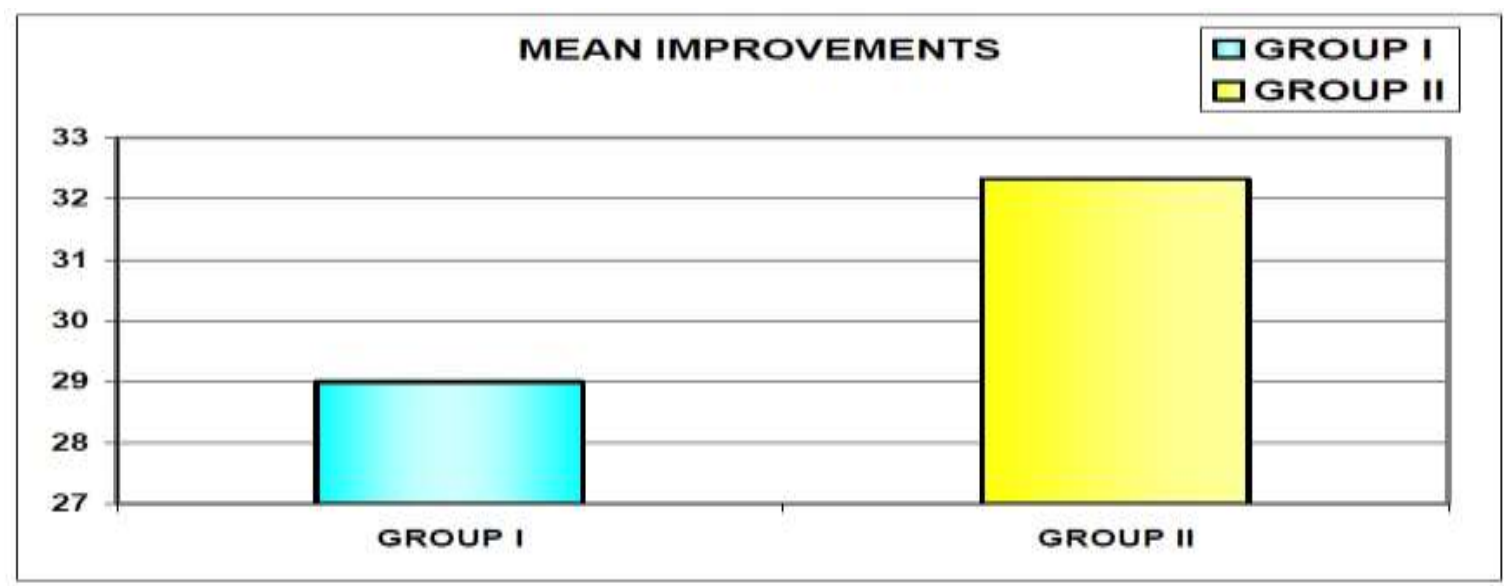

Graph-1:- WOMAC Osteoarthritis Index

Interpritation: The above Figure shows significant means improvements in both groups when measured with functional disability index

Table 6:- Functional disability index

\begin{tabular}{|l|l|l|l|l|}
\hline & & & & \\
& Mean & S.D & 't' Value & 't' Value From Table \\
\hline Group 1 & 1 & 0 & 2 & 2.04 \\
\hline Group 2 & 1.017 & 0.991 & & \\
\hline
\end{tabular}

Interpretation: The result were significant at $\mathrm{p}<0.05$ as $\mathrm{t}$ value is equal to the table value.

\section{FDI MEAN IMPROVEMENTS}

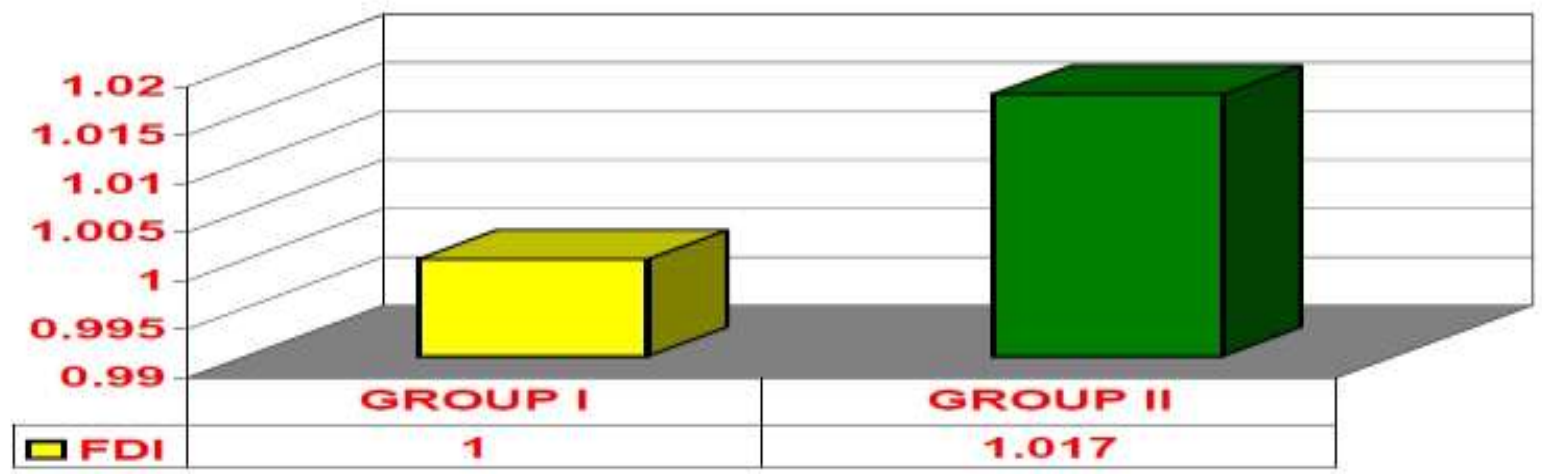

Graph-2:- Functional Disability Index

Interpretation: The above figure graph shows mean improvements in both groups when measures using functional disability index. 
The mean improvement in functional out comes for both the groups are presented in above tables. The data were analyzed with statistical interpretation and found the results as given below. There was significant improvement in functional outcome in both groups that is group-1 (treated with concentric strength training) and group 2 (treated with eccentric strength training exercises). The functional outcome improved in both groups after 6 weeks of treatment when measure with WOMAC and Functional disability index but there were better improvements shown by the group 2 treated with eccentric strength training.

The outcomes were found significant using t-test in case of WOMAC index and FDI. The values are found greater than that of table value at $p<0.05$. Hence the researcher can accept the experimental hypothesis, which says that there are significant differences between concentric, and eccentric strength training of quadriceps in improving the functional outcome in patients with primary osteoarthritis of knee joint.

\section{Discussion:-}

In this study the research aims to analyze better improvements in functional outcome by using concentric and eccentric strength training.

This study was done on 60 primary osteoarthritis patients who were divided in to experimental group 1(concentric strength training) and experimental group 2 (eccentric strength training) by convenience sampling.

The functional outcome was taken as the variable that was measured by WOMAC and FDI scores and that scale used were standard tools to analyze the functional outcome and this was supported by studies done by Sallafi et al, 2003 and Eswar krisnan et al,2004 respectively. Concentric strength training exercise were given to improve the functional outcome by improving quadriceps strength, this was supported by Michelle porter, 2002.

Eccentric strength training exercise were given to improve the functional outcome by improving quadriceps strength, this was supported by Hortobagyi et al, 1996.

The data were collected as per the Performa and analyzed with statically inference by using ' $t$ ' test. The ' $t$ ' test value shows that there were significant improvements in functional outcome in both the treatment groups but the group treated with eccentric form of strength training showed higher improvements. There results were in accord with those of Ying fang et al, 2001 and Hortobagyi et al, 1996 who did studies to improve quadriceps strength with these exercises.

Also studies by Pao FengTsai et al, 2002 and M V hurley et al supports our results, which prove that quadriceps strengthening exercise, improve functional outcome by reducing pain and disability of knee. This supports the experimental hypothesis. Hence, the researcher accepts the experimental hypothesis.

The functional outcome in osteoarthritis knee patients can be improved by using both forms of strength training exercise.

\section{Conclusion:-}

There was significant improvement in functional outcome in both groups that is group1 (treated with concentric strength training) and group 2 (treated with eccentric strength training exercises)

The results were found to be significant for functional outcome with eccentric strength training. Hence, eccentric strength training program should be incorporated in routinely treatment regimes to improve the functional outcome of with osteoarthritis of knee joint. 


\section{Reference:-}

1. Ad Milne, Na Evans And W.Dd. Stanish, Neo operative management of knee osteoarthritis woman. health in primary care 200,3(12)

2. David T. Felson Reva Clawerence,Paul A Dippr, Rosemarie Hirsch, Sharles S Kington Et Osteoarthritis : new insigts Anns of Int Med 2000 ; 133(8) 635-646.

3. Eswar Krishnan, Peter Tugwell And James F Fries Health Assessment Questionnaire As A Quality Indicator .Arth Res Ther 23004;6:505-513.

4. Frontera WR,Hugles VA, Fielding RA Et Al, aging of skeletal longitudinal study J. apple.physiol -2000 :88:1321-1326 (Medline).

5. Gail D Deyle Et Al Effectiveness Of Manual Physical Therapy And Exercise On O.A. Of Knee . Annals of Internal Medicine 200;182(3);173-81.

6. Hicks A.Loss of Strength In old Age: Is this aging or disuse? Presented at the alloa conference 1999.

7. Judith C Bautch Daniel And Malone And Arthur C Vails. Effects of exercise on knee joints with osteoarthritis. Jrahuematol.

8. Michelle Porter, the Power of Strength Training For Older Adults. Research Update 2002, Osteoarthritis

9. Michael V. Huxley David \& Scott, Joanne Rees, Di, New Ham. Sensorimotor changes and functional performance in patient with knee O.A. Ann Rheum $1997 ; 56: 614-648$.

10. Nicholas Babault, Micael Pousson, Anne Michaut And Jaques Van Hoecke, Effect Of Quadriceps Muscle Length On Neural Activation During Isometric And Concentric Contraction, J Appl Physiol 2003; 94;983-990.

11. Nish J. Manek, And Nancy E. Lane. Current Concepts In Diagnosis And Management, American Family Physician 2000.

12. Pao-Feng Tsai, Kathi Richards And Richard Fitz Randolph. Feasibility of using quadriceps, strengthening exercise to improve pain and sleep in severely demented elder with O.A., B.Sc. Nursing 2002, 1:1.

13. Rogers MA, Evanse WJ, changes in skeletal muscle with aging :training sport sci.rev 1993;21:65-102 (Medline)

14. Sallafi F, Leardini G, Canesi B, Reliability And Validity of WOMAC, Osteoarthritis Cartilage, 2003 Aug; 11(8):551-60.

15. Sheila C O Reilly Adrian Jones, Ken R Meeur, Michael Doherty. Quadriceps weakness in knee osteoarthritis : the effect on pain and disability.

16. Tiwari $\mathrm{M}$ et al., Effects of combined isotonic exercises protocol on unilateral symptomatic osteoarthritis knee International Journal of Therapies and Rehabilitation Research 2015; 4 (4): 132-137.

17. Thumboo J, Chew L H, Soh C H, Validation Of WOMAC Index In Asians With Osteoarthritis In Singapore, Osteoarthritis Cartilage, 2001jul;995:440-6.

18. Wayen Scott,Jennifer Stevens And Stuart Abinder -Macleod. Human skeletal mucle fiber types, phy. the.2001:81:1810-1816.

19. William Mc. Acdle, Exercise physiology phildelphia ; Lee \& febgre 1986.

20. Yin Fang Vlodek Siemioow, Vinos Sahgal, Greater Movement Related Cortival Potential During Human Eccentric Versus Concentric ,J. Neuro Physiol 2001;86;1764-1777. 